\title{
STUDI PEMBANGUNAN RUANG TERBUKA HIJAU PUBLIK DI KECAMATAN PONTIANAK KOTA PADA KOTA PONTIANAK
}

\author{
(Study Of The Developmet Of Green Open Space in Pontianak City sub-district in Pontianak City)
}

\section{Muhammad Haidar, Eddy Thamrin dan Siti Latifah}

Fakultas Kehutanan Universitas Tanjungpura, Jalan Imam Bonjol Pontianak 78124

Email : muhammadhaidar4993@gmail.com

\begin{abstract}
Green Open Space (RTH) is an area that extends / lanes and or groups, which use more open, where plants grow, both those that grow plants naturally and deliberately planted. In Law No. 26 of 2007, specifically mandates the need for the provision and utilization of green open spaces, the proportion of which is set at least $30 \%$ percent of the total area of the city, namely (20\% of public green space and 10\% private RTH). The study aims to determine the suitability of the implementation of green open space development in Pontianak city sub-district with Pontianak City RTRW and find out the causes that are not achieved if the green open space has not run smoothly. The research method used a survey method and ground check of green open space distribution in Pontianak city sub-district. The interview technique was to find out the perceptions of the surrounding community towards RTH areas in Pontianak Kota Sub-district. The results of the study from the Interpretation of IKONOS 2017 Images and the 2018 ground check in Pontianak Kota District in the year there were 22 green open spaces. The area of calculation of Existing and RTRW 2013-2033 almost reached the target, RTH Park reached 98.63\%, RTH Funeral 89.83\%, RTH Field 94.96\%, and RTH Green Line had reached $104 \%$ of the RTRW 2013-2033
\end{abstract}

Keywords: Development, Green Open Space, Pontianak, RTH Public

\section{PENDAHULUAN}

Ruang Terbuka Hijau (RTH) adalah area yang memanjang berbentuk jalur dan atau area mengelompok, yang penggunaannya lebih bersifat terbuka, tempat tumbuh tanaman, baik yang tumbuh secara alamiah maupun yang sengaja di tanam. Penataan RTH tertuang di dalam Undang-undang No. 26 tahun 2007 tentang penataan ruang yang menyebutkan bahwa 30\% wilayah kota harus berupa RTH yang terdiri dari $20 \%$ publik dan $10 \%$ privat. RTH publik adalah RTH yang dimiliki dan dikelola oleh pemerintah daerah kota/kabupaten yang digunakan untuk kepentingan masyarakat secara umum. Contoh RTH Publik adalah taman kota, hutan kota, sabuk hijau (green belt), RTH di sekitar sungai, pemakaman, dan rel kereta api. Sedangkan RTH Privat adalah RTH milik institusi tertentu atau orang perseorangan yang pemanfaatannya untuk kalangan terbatas antara lain berupa kebun atau halaman rumah/gedung milik masyarakat/swasta yang ditanami tumbuhan.

$$
\text { Ruang Terbuka Hijau (RTH) }
$$
perkotaan adalah bagian dari ruang-ruang terbuka (open space) suatu wilayah perkotaan yang diisi oleh tumbuhan, tanaman dan vegetasi (endemik maupun introduksi guna mendukung manfaat ekologis sosial-budaya dan arsitektural yang dapat memberikan manfaat ekonomi 
(kesejahteraan) bagi masyarakatnya. Fungsi ruang terbuka hijau pada wilayah perkotaan sangat banyak, yaitu dari aspek fungsi ekologis, sosial/budaya, arsitektural, dan ekonomi. Secara ekologis ruang terbuka hijau dapat meningkatkan kualitas air tanah, mencegah banjir, mengurangi polusi udara, dan menurunkan suhu kota tropis yang panas terik. Bentukbentuk RTH perkotaan yang berfungsi ekologis antara lain seperti sabuk hijau kota, taman, hutan kota, jalur sempadan sungai dan lain-lain.

Fungsi RTH di perkotaan menurut Simonds (1983), memiliki fungsi utama yaitu fungsi ekologis, dan fungsi tambahan yaitu fungsi arsitektural, sosial, dan fungsi ekonomi. Dalam suatu wilayah perkotaan empat fungsi utama ini dikombinasikan sesuai dengan kebutuhan, kepentingan, dan keberlanjutan kota.

RTH berfungsi ekologis, yag menjamin keberlanjutan suatu wilayah kota secara fisik, harus merupakan satu bentuk RTH yang berlokasi, berukuran, dan berbentuk pasti dalam satu wilayah kota, seperti RTH untuk perlindungan sumberdaya penyangga kehidupan manusia dan untuk membangun jejaring habitat kehidupan liar. RTH untuk fungsifungsi lainnya (sosial, ekonomi, struktural) merupakan RTH pendukung dan penambah nilai kualitas lingkunga dan budaya kota tersebut sehingga dapat berlokasi dan berbentuk sesuai dengan kebutuhan dan kepentingannya, seperti untuk keindahaan, rekreasi, dan pendukung arsitektur kota.

Tujuan penelitian untuk mengetahui kesesuaian pelaksanaan pengembangan
RTH yang ada di kecamatan Pontianak kota dengan RTRW Kota Pontianak dan mencari tahu penyebab tidak tercapainya apabila RTH belum berjalan dengan lancar maka mencari solusi atau penyelesaian kegiatan RTH yang tidak berjalan lancar di kecamatan Pontianak kota.

\section{METODE PENELITIAN}

Penelitian ini dilakukan pada bulan Juli 2018 Di Kecamatan Pontianak Kota selama 3 minggu. Objek penelitian adalah Ruang Terbuka Hijau (RTH), serta masyarakat di sekitar kawasan RTH, Pemerintah, serta pemuka masyarakat di Kecamatan Pontianak Kota. Alat yang digunakan dalam penelitian ini adalah Citra Ikonos tahun 2017 Kota Pontianak, kuisioner penelitian, peta lokasi penelitian, peta RTRW Kota Pontianak 2013-2033, menggunakan software Arcgis 10.2.

Penelitian menggunakan metode survey lapangan tiap kawasan RTH untuk menentukan respon masyarakat menggunakan teknik wawancara dibantu dengan kuisioner.Variabel penelitian adalah Komponen fisik dan Komponen Sosial, komponen fisik menentukan ketepatan lokasi dari yang direncanakan dengan kondisi eksisting serta realisasi perkembangan antara eksisting dan rencana. Komponen sosial terkait dengan pengetahuan dari sekitar masyarakat kawasan RTH tentang keberadaan RTH respon atau persepsi masyarakat terkait adanaya Ruang Terbuka Hijau. Pengumpulan data yang dikumpulkan meliputi data primer dan data sekunder. Data primer meliputi titik koordinat lokasi keberadaan RTH, Luasan kondisi eksisting RTH, dan dari data sosial dengan 
wawancara. Data sekunder meliputi data titik koordinat luasan RTH dan data luasan Rencana RTH.

Teknik pengambilan data dilakukan dengan teknik survey menentukan titik lokasi RTH dengan bantuan GPS, sedangkan teknik wawancara untuk mengisi kuisioner dari aspek sosial terhadap pentingnya RTH di Kecamatan Pontianak Kota dengan melihat respon dan persepsi masyarakat sekitar kawasan RTH. Ketepatan koordinat lokasi menggunakan perhitungan uji $\mathrm{T}$ berpasangan (Paired $T$ test) dari hasil interpretasi Eksisting dan Rencana sebagai berikut :

$$
\begin{aligned}
& \mathbf{t}=\frac{\bar{X}_{1}-\bar{X}_{2}}{S_{g b}^{2} \sqrt{\frac{S_{1}^{2}}{n_{1}}+\frac{S_{2}^{2}}{n_{2}}}} \\
& S_{g b}^{2}=\frac{\left(n_{1}-1\right) S_{1}^{2}+\left(n_{2}-1\right) S_{2}^{2}}{\left(n_{1}+n_{2}\right)-2}
\end{aligned}
$$

Keterangan:

$\bar{X}_{1}=$ nilai rata-rata sampel pertama.

$\bar{X}_{2}=$ nilai rata-rata sampel ke dua.

$S_{g b}^{2}=$ taksiran varians gabungan populasi

$\mathrm{N} 1=$ jumlah sampel populasi pertama

N2 = jumlah sampel populasi kedua.

$S_{1}^{2}=$ varians sampel pertama.
$S_{2}^{2}=$ varians sampel kedua.

Sumber: Anwar, 2011:128

Dengan keputusan:

1. Jika nilai sig. thitung $>$ tabel maka tidak terdapat perbedaan signifikan

2. Jika nilai sig. thitung $<$ tabel maka terdapat perbedaan signifikan

Perhitungan luasan perkembangan dengan menggunakan formula sebagai berikut:

$$
p=\frac{\text { Luas eksisting }}{\text { Luas rencana }} \times 100 \%
$$

Keterangan:

$\mathrm{P}$

: Kesesuaian pelaksanaan

\section{RTH}

Luas Eksisting : Luasan dari hasil eksisting.

Luas Rencana : Luasan yang sudah direncanakan dari RTRW

Analisis potensi sosial menggunakan data hasil kuesioner yang kemudian dirangking berdasarkan tingkatan tertinggi hingga terendah yang kemudian diharkat sesuai dengan rangking tersebut. Total nilai dijumlah dan dirangking sesuai dengan tingkatan keberlanjutan yang telah dibuat sehingga menghasilkan tingkat respon masyarakat terhadap RTH di Kecamatan Pontianak Kota.

Posisi keputusan penelitian adalah:

\section{Tabel 1. Penilaian Skor Persepsi}

\begin{tabular}{cl}
\hline Skor Rataan & \multicolumn{1}{c}{ Keterangan } \\
\hline $1,0-1,8$ & Sangat tidak setuju/Sangat tidak tahu \\
$1,8-2,6$ & Tidak setuju/Tidak tahu \\
$2,6-3,4$ & Ragu-ragu \\
$3,4-4,2$ & Setuju/Tahu \\
$4,2-5,0$ & Sangat setuju/Sangat tahu \\
\hline
\end{tabular}

Sumber : Sugiyono 2013

Penentuan rangking persepsi: 
Tabel 2. Rangking Persepsi

\begin{tabular}{ccc}
\hline Kelas Skor & Skala skor & Persepi \\
\hline 1 & $\leq 20 \%$ & Rendah \\
2 & $21 \% \leq 40 \%$ & Rendah \\
3 & $41 \% \leq 60 \%$ & Sedang \\
4 & $61 \% \leq 80 \%$ & Tinggi \\
5 & $\geq 80 \%$ & Tinggi \\
\hline
\end{tabular}

Sumber: Sugiyono, 2013

\section{HASIL DAN PEMBAHASAN}

Lokasi RTH di Kecamatan Pontianak Kota

Berdasarkan hasil interpretasi citra yang sudah terklasifikasikan, terdapat 22 Ruang Terbuka Hijau Publik di
Kecamatan Pontianak Kota Kalimantan Barat (Tabel 3), jenis RTH tersebut ialah RTH Pemakaman, RTH Taman Kota , RTH Jalur Hijau, RTH Hutan Kota dan RTH Lapangan Olahraga.

Tabel 3. Sebaran Ruang Terbuka Hijau Publik Kecamatan Pontianak Kota.

\begin{tabular}{clcc}
\hline \multirow{2}{*}{ No } & & \multicolumn{2}{c}{ Luas } \\
\cline { 3 - 4 } & & Eksisting(Ha) & Rencana(Ha) \\
\hline 1 & TPU Muslim jl.danau sentarum & 0,93 & 0,97 \\
2 & TPU Sungai Bangkong & 3,11 & 3,67 \\
3 & Lapangan Gang Hanura & 0,98 & 1,05 \\
4 & Lapangan JL.Kesehatan & 1,26 & 1,26 \\
5 & Taman Bundaran Pelindo & 0,46 & 0,46 \\
6 & RTH Ampera depan gg.Pardidi & 10,52 & 10,61 \\
7 & RTH Ampera Stadion Atletik & 5,01 & 5,11 \\
8 & TPU JL. Kutilang & 1,56 & 1,56 \\
9 & TPU Jl. Lembah Murai 1 & 0,14 & 0,21 \\
10 & TPU Gg. Merak II & 0,16 & 0,19 \\
11 & Taman Simpang Ampera & 1,04 & 1,04 \\
12 & Jalur Hijau Median dan Bahu Jalan & 0,26 & 0,25 \\
13 & TPU R.A. Kartini & 0,91 & 1,01 \\
14 & TPU Gg. Waspada V & 0,15 & 0,17 \\
15 & Lapangan Jl. Sejarah & 0,90 & 1,05 \\
16 & TPU A.R Hakim & 0,59 & 0,62 \\
17 & TPU Lembah Murai 2 & 0,06 & 0,06 \\
18 & Taman JL.Karimata & 0,67 & 0,97 \\
19 & Taman Jam Tua & 0,02 & 0,02 \\
20 & Taman Tugu Pancasila & 0,07 & 0,07 \\
21 & Lapangan Olahraga Kebon Sajoek & 1,63 & 1,66 \\
22 & Taman Alun-Alun Kapuas & 2,48 & 2,27 \\
\hline & Total & 32,91 & 34,05 \\
\hline
\end{tabular}

Sumber: Data Hasil Analisis 2018 
Berdasarkan hasil interpretasi Citra Ikonos 2017 dan memeriksa lapangan/ koordinat setiap RTH dapat diketahui (Gambar 1). Selanjutnya luasan setiap RTH dihitung dengan menggunakan calculate geometry. Berdasarkan perhitungan luasan dapat dilihat pada tabel 3. RTH terluas adalah RTH Taman Ampera depan Gg. Pardidi seluas 10,52 Ha dimana RTH Tersempit adalah RTH Taman Jam Tua seluas $0,02 \mathrm{Ha}$.

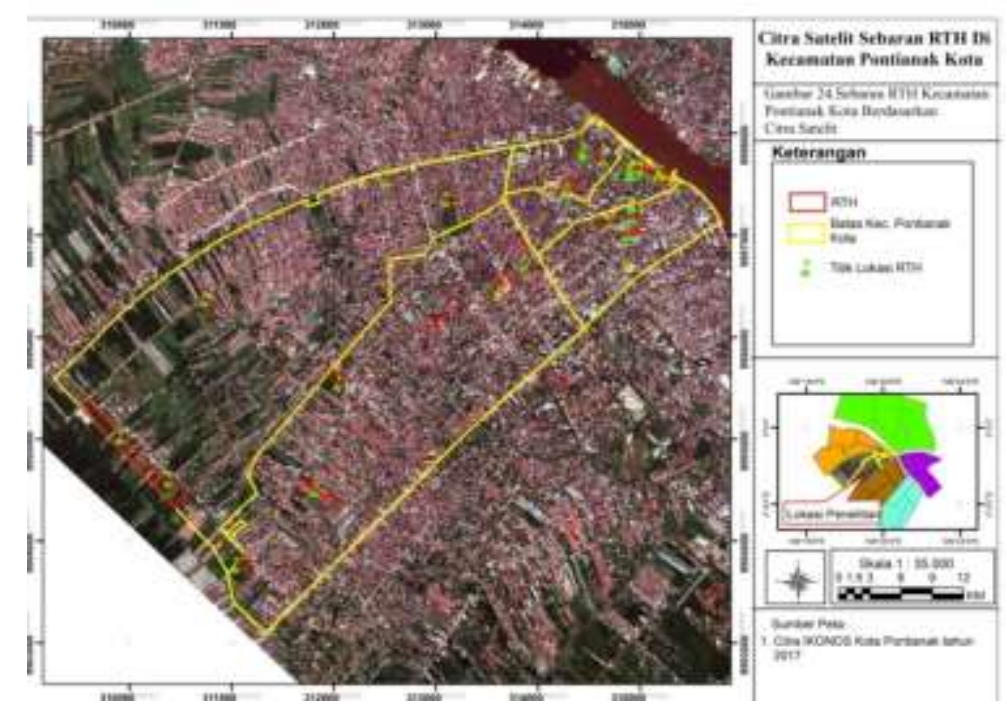

Gambar 1. Peta Citra Ikonos 2017 Sebaran RTH di Kecamatan Pontianak Kota (2017 Ikonos Image Map RTH distribution in Pontianak Kota District)

Kesesuaian Lokasi

Berdasarkan rata-rata luasan dengan menggunakan Uji $\mathrm{T}$ Berpasangan (Paired T-Test) untuk mengetahui apakah ada perbedaan sesuai atau tidaknya lokasi pengamtan dengan yang sudah direncanakan menurut RTRW Kota Pontianak 20132033 dilakukan analisis Uji $\mathrm{T}$ Berpasangan ( Paired Samples Test ).

Tabel 4. Data Hasil Ringkasan Statistik Deskriptif dari Kedua Sampel atau data EKSISTING dan RENCANA

\begin{tabular}{lcccr}
\hline \multicolumn{1}{c}{ Perlakuan } & Mean & N & Std.Devitiation & Std. Error Mean \\
\hline EKSISTING & 1,4848 & 22 & 2,34394 & 0,49973 \\
RENCANA & 1,5481 & 22 & 2,37322 & 0,50597 \\
\hline Sumber: Data Hasil Analisis 2018 & & &
\end{tabular}

Tabel 5. Analisis Uji T Berpasangan ( Paired Samples Test )

\begin{tabular}{|c|c|c|c|c|c|c|}
\hline \multirow[b]{2}{*}{ Perlakuan } & \multicolumn{3}{|c|}{ Paired Differences } & \multirow[b]{2}{*}{$\mathrm{T}$} & \multirow[b]{2}{*}{ df } & \multirow{2}{*}{$\begin{array}{l}\text { Sig. } \\
(2- \\
\text { tailed) }\end{array}$} \\
\hline & Mean & Std.Deviation & $\begin{array}{l}\text { Std.Error } \\
\text { Mean }\end{array}$ & & & \\
\hline Pair 1 EKSISTING - RENCANA &,- 06332 & 14312 & 03051 & -2.075 & 21 & 0.050 \\
\hline
\end{tabular}


Hasil uji statistik di atas berdasarkan pengujian menggunakan uji compare mean T-test, dapat ditemukan hasil bahwa perlakuan terhadap kondisi Eksisting dan Rencana tidak mengalami perbedaan yang signifikan sebelum dan sesudah privatisasi dengan nilai signifikansi lebih dari alpha $10 \%$ atau Luasan Perkembangan
0,1 . Variabel tersebut memiliki nilai standar deviasi atau simpang baku antara selisih sebelum dan sesudah privatisasi sebesar 0,143 dengan nilai $t$ sebesar -2,075. Rasio ini diukur dengan jumlah data sebanyak 22. Hipotesis yang dapat ditarik dari penelitian ini adalah terima $\mathrm{H}_{0}$, tolak $\mathrm{H}_{1}$.

Tabel 6. Luasan Perkembangan RTH Kecamatan Pontianak Kota berdasarkan hasil Eksisting 2018 dan Rencana 2013-2033.

\begin{tabular}{llccc}
\hline \multirow{2}{*}{ No } & \multirow{2}{*}{ Jenis RTH } & \multicolumn{2}{c}{ Luas } & $\begin{array}{c}\text { Persentase } \\
\text { Perkembangan RTH } \\
(\%)\end{array}$ \\
\cline { 3 - 4 } & & Eksisting(Ha) & Rencana (Ha) & $89,83 \%$ \\
\hline 1 & RTH Pemakaman Umum & 7,60 & 8,46 & $98,63 \%$ \\
2 & RTH Taman & 20,28 & 20,56 & $94,96 \%$ \\
3 & RTH Lapangan & 4,76 & 5,02 & $104,00 \%$ \\
4 & RTH Jalur Hijau & 0,26 & 0,25 & \\
\hline
\end{tabular}

Sumber: Data Hasil Analisis 2018

Berdasarkan Tabel 6 persentase

Tertentu/Lapangan Olahraga 94.96\%, perkembangan RTH menunjukkan persentase terbesar pada RTH Jalur hijau sebesar 104,00 \%, diikuti dengan dan yang terendah RTH Pemakaman Umum/TPU di kecamatan Pontianak Kota $89.83 \%$.

RTH Taman 98.63\%, RTH Fungsi

\section{RTH Pemakaman Umum}

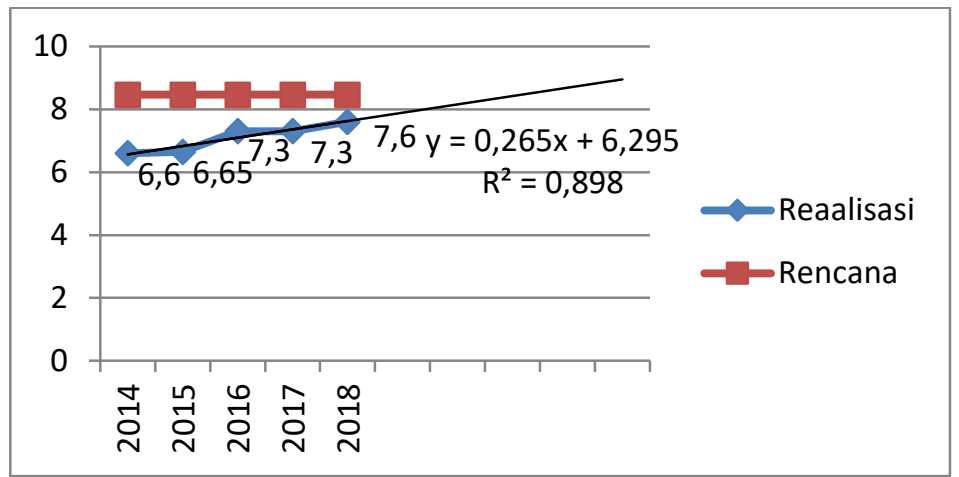

Gambar 2. Grafik Realisasi dan Rencana RTH Publik Pemakaman Umum (Realization Charts and Public Open Space Plans for public cemeteries) 
Berdasarkan Gambar 2. Maka dibuat prediksi perkembangan RTH Pemakaman Umum (Tabel 7).

Tabel 7. Proyeksi RTH Pemakaman Umum.

\begin{tabular}{cccc}
\hline \multicolumn{3}{c}{ Proyeksi } \\
\hline Tahun & Luas (Ha) & Tahun & Luas (Ha) \\
\hline 2014 & 6,60 & 2019 & 7,89 \\
2015 & 6,65 & 2020 & 8,15 \\
2016 & 7,31 & 2021 & 8,42 \\
2017 & 7,39 & 2022 & 8,68 \\
2018 & 7,60 & 2023 & 8,95 \\
\hline
\end{tabular}

Keterangan : Tahun $($ hitam $)=$ belum mencapai target, Tahun $($ merah $)=$ prediksi target tercapai

Berdasarkan Tabel 7 dan Gambar 1 dapat diketahui proyeksi luas pemakaman umum pada tahun 2014 6,60 Ha, di tahun 2019 diprediksi terus mengalami peningkatan menjadi 7,89 Ha, pada tahun 2020 menjadi $8,15 \mathrm{Ha}$, tahun 2021 menjadi 8,42 Ha, tahun
2022 menjadi 8,68 Ha, tahun 2023 menjadi 8,95. Berdasarkan hasil peramalan tersebut dapat diketahui bahwa pada tahun 2022 dan 2023 luas pemakaman umum kecamatan Pontianak Kota dapat mencapai rencana yang telah ditetapkan.

\section{RTH Taman Kota}

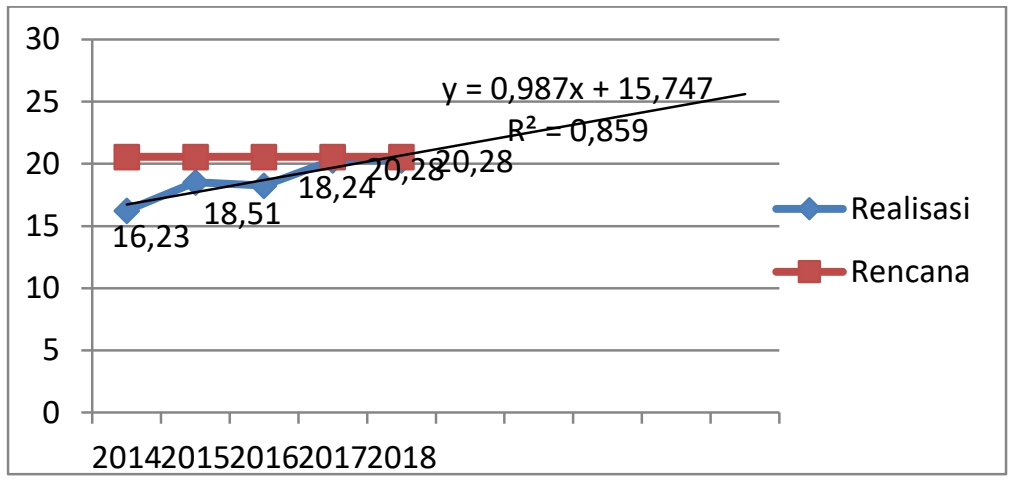

Gambar 3. Grafik Realisasi dan Rencana RTH Publik Taman Kota (Graph of Realization and Plans for Public Opened Urban Park)

Berdasarkan gambar 3. Maka dibuat prediksi perkembangan RTH Taman Kota (Tabel 8).

Tabel 8. Proyeksi RTH Taman Kota.

\begin{tabular}{cccc}
\hline \multicolumn{3}{c}{ Proyeksi } \\
\hline Tahun & Luas $(\mathrm{Ha})$ & Tahun & Luas $(\mathrm{Ha})$ \\
\hline 2014 & 16,23 & 2019 & 21,66 \\
2015 & 18,51 & 2020 & 22,65 \\
2016 & 18,24 & 2021 & 23,64 \\
2017 & 20,28 & 2022 & 24,62 \\
2018 & 20,28 & 2023 & 25,61 \\
\hline Keterangan : Tahun (hitam) $=$ belum mencapai target, Tahun (merah) =prediksi target tercapai
\end{tabular}


Berdasarkan Tabel 8 dapat diketahui proyeksi luas taman pada tahun 2014 16,23 Ha, di tahun 2019 diprediksi terus mengalami peningkatan menjadi 21,66 Ha, pada tahun 2020 menjadi 22,65 Ha, tahun 2021 menjadi 23,64 Ha, tahun 2022 menjadi 24,62
Ha, tahun 2023 menjadi 25,61. Berdasarkan hasil peramalan tersebut dapat diketahui bahwa pada tahun 2019 luas taman kota di kecamatan Pontianak Kota dapat mencapai rencana yang telah ditetapkan.

\section{Jalur Hijau}

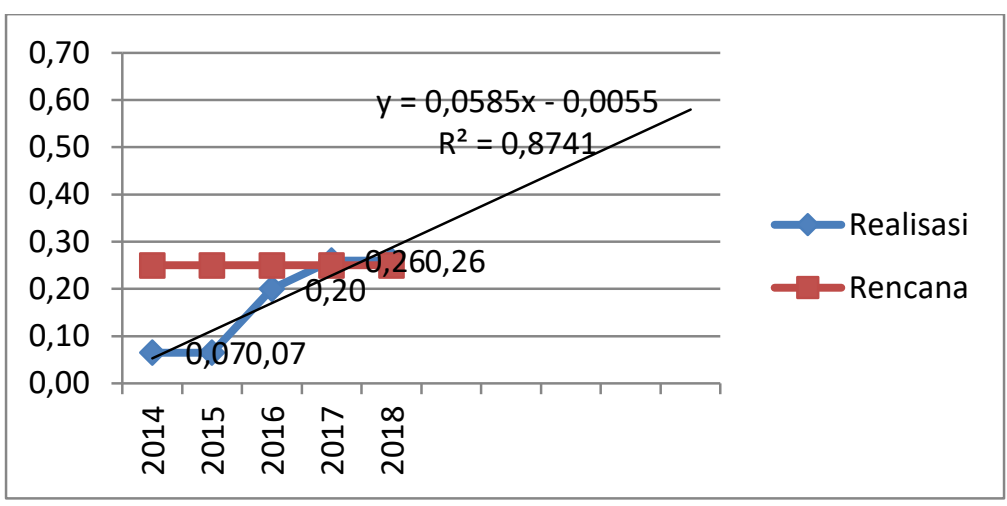

Gambar 4. Grafik Realisasi dan Rencana RTH Publik Jalur Hijau (Realization Chart and Green Line Public Open Space Plan)

Berdasarkan Gambar 4. Maka dibuat prediksi perkembangan RTH Jalur Hijau(Tabel 9).

Tabel 9. Proyeksi Jalur Hijau.

\begin{tabular}{cccc}
\hline \multicolumn{3}{c}{ Proyeksi } \\
\hline Tahun & Luas (Ha) & Tahun & Luas (Ha) \\
2014 & 0.07 & 2019 & 0.34 \\
2015 & 0.07 & 2020 & 0.40 \\
2016 & 0.20 & 2021 & 0.46 \\
2017 & 0.26 & 2022 & 0.52 \\
2018 & 0.26 & 2023 & 0.58
\end{tabular}

Keterangan $:$ Tahun $($ hitam $)=$ belum mencapai target, Tahun $($ merah $)=$ prediksi target tercapai

Berdasarkan Tabel 9 dapat diketahui proyeksi luas jalur hijau pada tahun 2014 0,07 Ha, di tahun 2019 diprediksi terus mengalami peningkatan menjadi 0,34 Ha, pada tahun 2020 menjadi 0,40 Ha, tahun 2021 menjadi
0,46 Ha, tahun 2022 menjadi 0,52 Ha, tahun 2023 menjadi 0,58. Berdasarkan hasil peramalan tersebut dapat diketahui bahwa pada tahun 2017 luas jalur hijau di kecamatan Pontianak Kota sudah mencapai target yang telah ditetapkan. 


\section{Lapangan Olahraga}

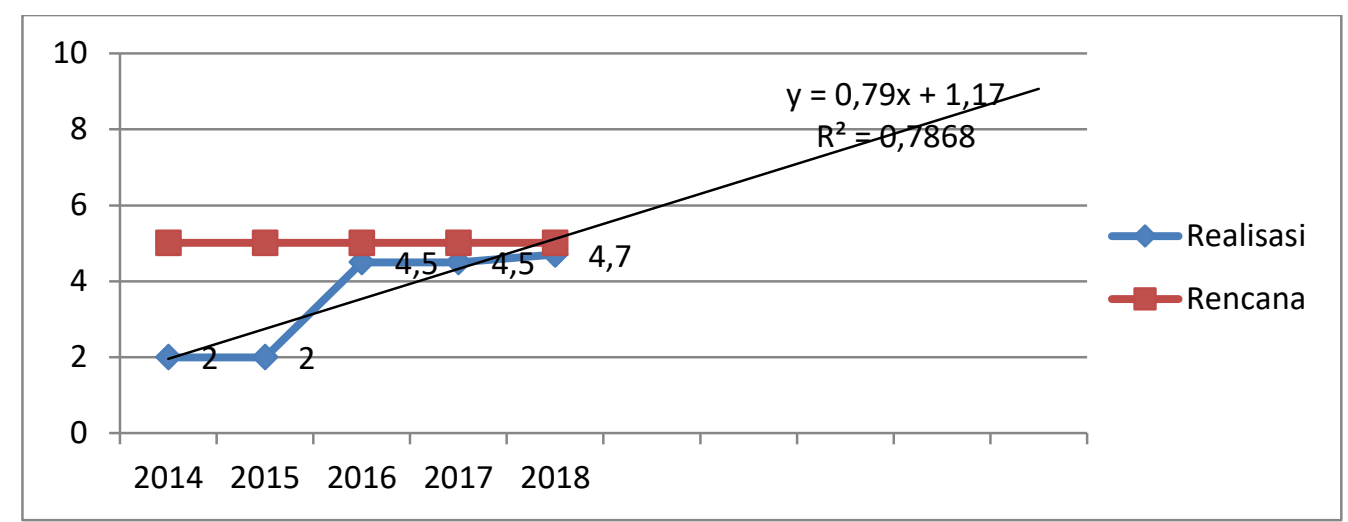

Gambar 5. Grafik Realisasi dan Rencana RTH Publik Lapangan Olahraga (Realization Charts and Public Green Open Space Plans)

Berdasarkan Gambar 5. Maka dibuat prediksi perkembangan RTH Lapangan olahraga (Tabel 10).

Tabel 10. Proyeksi RTH Lapangan.

\begin{tabular}{cccc}
\hline Tahun & Luas (Ha) & $\begin{array}{c}\text { Proyeksi } \\
\text { Tahun }\end{array}$ & Luas (Ha) \\
\hline 2014 & 2,0 & 2019 & 5,91 \\
2015 & 2,0 & 2020 & 6,70 \\
2016 & 4,5 & 2021 & 7,49 \\
2017 & 4,5 & 2022 & 8,28 \\
2018 & 4,7 & 2023 & 9,07 \\
\hline
\end{tabular}

Keterangan : Tahun $($ hitam $)=$ belum mencapai target, Tahun $($ merah $)=$ prediksi target tercapai

Berdasarkan Tabel 10 dapat kecamatan Pontianak Kota sudah diketahui proyeksi luas lapangan mencapai target yang telah ditetapkan. olahraga pada tahun 2014 2,0 Ha, di tahun 2019 diprediksi terus mengalami peningkatan menjadi 5,91 $\mathrm{Ha}$, pada tahun 2020 menjadi $6,70 \mathrm{Ha}$, tahun 2021 menjadi 7,49 Ha, tahun 2022 menjadi 8,28 Ha, tahun 2023 menjadi 9,07 Ha. Berdasarkan hasil peramalan tersebut dapat diketahui bahwa pada tahun 2019 luas Lapangan Olahraga di

Persepsi Masyarakat

Berdasarkan hasil penelitian terhadap 110 responden diperoleh 23 responden atau $20.91 \%$ yang mempunyai penilaiian tinggi, 67 responden atau $60.91 \%$ bersikap sedang dan 20 responden atau $18.18 \%$ bersikap negatif. Dapat dilihat pada Tabel 18 berikut ini

Tabel 18. Frekuensi Persepsi Masyarakat Kecamatan Pontianak Kota Terhadap Ruang Terbuka Hijau di sekitar Kecamatan pontianak Kota.

\begin{tabular}{cccc}
\hline No. & Persepsi & Frekuensi & Persen \% \\
\hline 1 & Tinggi & 23 & 20,91 \\
2 & Sedang & 67 & 60,91 \\
3 & Rendah & 20 & 18,18 \\
\hline Jumlah & & 110 & 100,00 \\
\hline
\end{tabular}

Sumber: Data Hasil Analisis 2018 
Hal ini menunjukan bahwa respon dari masyarakat Kecamatan Pontianak Kota menganggap dengan adanya Ruang Terbuka Hijau cenderung sedang, dikarenakan masih banyak masyarakat yang tidak paham tentang kawasan Ruang Terbuka Hijau. Masyarakat yang memiliki respon Tinggi menganggap bahwa dengan adanya Ruang Terbuka Hijau maka daerah sekitar kawasan tempat tinggal mereka lebih nyaman, indah, dan mendapat udara segar. Sedangkan masyarakat yang memiliki persepsi rendah menganggap tidak terlalu paham tentang adanya manfaat Ruang Terbuka Hijau.

Pelaksanaan Ruang Terbuka Hijau Di Kecamatan Pontianak Kota.

Dari hasil analisis dengan menggunakan analisis Uji $\mathrm{T}$ berpasangan dan Analisis Trend, diketahui bahwa RTH di Kecamatan Pontianak Kota memiliki perbedaan yang signifikan dari RTRW Kota Pontianak tahun 2013-2033 dimana di dalam rencana yang ditetapkan belum mencapai luasan yang telah terealisasi menyebabkan pelaksanaan RTH di Kecamatan Pontianak Kota belum mencapai dari yang ditargetkan.

Hal ini disebabkan terjadinya alih fungsi lahan ruang terbuka hijau salah satunya adalah karena investor mengubah lahan-lahan tersebut menjadi pembangunan gedung seperti kantor, toko - toko, dan sebagian besar dipenuhi kafe serta pemukiman.Ini menyebabkan banyak lahan ruang terbuka hijau di alih fungsikan sebagai perumahan sehingga ruang terbuka hijau di Kecamatan Pontianak Kota belum mencapai target yang ditentukan pada tahun 2018.

Penyelesaian Pencapaian RTH Agar Berjalan Lancar

Berdasarkan hasil respon masyarakat kebanyakan masyarakat di sekitar kawasan ruang terbuka hijau ada yang paham dan ada juga yang tidak paham, masyarakat kebanyakan mengenal ruang terbuka hijau dengan hutan kota hal ini perlu dilakukan pemerintah dalam membuat legalitas formal terhadap kawasan RTH yang ada di Kecamatan Pontianak Kota agar pengelolaan, pemeliharaan RTH di Kecamatan Pontianak Kota berjalan lancar, karena sebagian besar masyarakat di Kecamatan Pontainak Kota siap berpartisipasi dalam menjaga dan melestarikan keberlangsungan ruang terbuka hijau bila diajak ikut andil oleh pemerintah.

\section{Kesimpulan}

Berdasarkan tujuan dan hasil analisis penelitian dapat ditarik kesimpulan sebagai berikut:

1. Hasil perhitungan luasan RTH di kecamatan Pontianak Kota berdasarkan Eksisting dan RTRW menggunakan Analisis Statistic Uji Paired Sample T-test dapat disimpulkan bahwa tidak ada perbedaan yang signifikan antara eksisting dan rencana artinya antara kondisi eksisting dan rencana tidak terdapat perbedaan signifikan. Meskipun dari yang telah direncanakan sudah ada yang 
mencapai target seperti RTH Taman dan RTH Jalur Hijau, namun pada RTH Pemakaman dan RTH Lapangan masih belum mencapai yang ditargetkan.

2. Penyebab belum tercapainya pelaksanaan RTH dilihat dari Analisis Trend dikarenakan meningkatnya pertumbuhan penduduk sehingga banyak lahan di alih fungsikan sebagai perumahan, gedung perkantoran, kafe pinggir jalan.

3. Persepsi masyarakat di kecamatan Pontianak Kota terhadap adanya Ruang Terbuka Hijau masih cenderung sedang. Salah satu solusi untuk mencapai target luas RTH adalah edukasi masyarakat tentang Ruang Terbuka Hijau mulai dari tingkat RT.

\section{Saran .}

1. Perlunya evaluasi ulang terhadap penggunaan lahannya dari tahun ke tahun di kawasan strategis kota (KSK) sesuai dengan kebijakankebijakan yang sesuai dalam Peraturan Perundanng-Undangan Republik Indonesia maupun Perda Kota Pontianak Tentang RTRW.

2. Dalam penelitian ini perlu dilakukan penelitian lanjutan di kecamatankecamatan Kota Pontianak lainnya, sehingga dapat disimpulkan ketersediaan RTH di Kota Pontianak sudah mencapai target atau belum.

3. Sosialisasi lebih ditingkatkan lagi supaya masyarakat dapat mengerti bagaimana pentingnya RTH bagi Kota Pontianak.
DAFTAR PUSTAKA

Pemerintah Kota Pontianak Badan Perencanaan Pembangunan Daerah, 2012. Master Plan RTH Kota Pontianak.Pontianak, Kalimantan Barat.

Peraturan Menteri pekerjaan Umum Nomor: 05/PRT/M/2008 tentang Pedoman Penyediaan dan Pemanfaatan Ruang Terbuka Hijau di Kawasan Perkotaan.

Sugiyono, 2013. Strategi Pembelajaran Pendidikan Karakter. Bandung: PT. Remaja Rosdakarya.

Sukristriyanti, dkk. 2009. Pendeteksian kerapatan vegetasi dan suhu permukaan menggunakan citra landsat studi kasus : Jawa Barat bagian selatan dan sekitarnya. Jurnal Riset Geologi dan Pertambangan Jilid 19 No.1 (2009) 15-24

Sulistyantara B. 2002. Sistem dan bentuk Ruang Terbuka Hijau Kota. Bogor: Jurusan Budidaya Pertanian, Fakultas Pertanian, IPB.

Undang-undang Republik Indonesia Nomor 26 Tahun 2007 tentang Penataan Ruang. Jakarta: Pemerintah Republik Indonesia

Utami, 2013. Metode Analisis Trendline.https://www.academia.e du/3724866/Perama lanTrendline. (23 Februari 2013). 